Conclusion: The 6MST is a valid test to evaluate exercise capacity in patients with AS. It is also an appropriate alternative to the 6MWT for determining exercise capacity when the 6MWT is not feasible due to technical restrictions. The 6MST can be proposed as a new exercise capacity evaluation tool in AS, as it is valid, reliable, portable and inexpensive.

References:

[1] van der Esch, Martin, et al. Respiratory muscle performance as a possible determinant of exercise capacity in patients with ankylosing spondylitis. Australian Journal of Physiotherapy, 2004;50(1):41-46

[2] ATS Committee on Proficiency Standards for Clinical Pulmonary Function Laboratories. ATS statement: guidelines for the six-minute walk test. Am J Respir Crit Care Med. 2002;166(1):111-117.

[3] Grosbois JM, Riquier C, Chehere B, et al. Six-minute stepper test: a valid clinical exercise tolerance test for COPD patients. Int $\mathrm{J}$ Chron Obstruct Pulmon Dis. 2016;11:657-663.

Disclosure of Interests: None declared

DOI: 10.1136/annrheumdis-2020-eular.2769

\section{THU0609-HPR RESPONSIVENESS OF THE DISABILITIES OF THE ARM, SHOULDER AND HAND (DASH) AND THE UPPER EXTREMITY FUNCTIONAL INDEX (UEFI) IN PATIENTS WITH POSTTRAUMATIC ELBOW STIFFNESS}

T. Birinci ${ }^{1}$, E. Kaya Mutlu², S. Altun ${ }^{3} .{ }^{1}$ Istanbul Medeniyet University, Department of Physiotherapy and Rehabilitation, Istanbul, Turkey; ${ }^{2}$ Istanbul University-Cerrahpasa, Department of Physiotherapy and Rehabilitation, Istanbul, Turkey; ${ }^{3}$ Bakirkoy Dr. Sadi Konuk Training and Research Hospital, Clinics of Orthopedics and Traumatology, Istanbul, Turkey

Background: There are many patient-rated outcome measures to assess the subjective component of function in musculoskeletal disorders of elbow. The first step of functional assessment is to select the instrument, which is sufficiently responsive. Although the disabilities of the arm, shoulder and hand (DASH) and the upper extremity functional index (UEFI) are widely used in reporting outcomes in upper extremity function, the responsiveness of these two scales has not been investigated in elbow disorders.

Objectives: This study aimed to compare and report the responsiveness of the DASH and the UEFI in patients with posttraumatic elbow stiffness.

Methods: Fifty-seven patients with posttraumatic elbow stiffness (32 women; mean age, $44.54 \pm 6.51$ years) were included. All patients completed the DASH and UEFI at baseline and after a six-week intervention, which was a structured exercise program. Patients who improved (much improved and slightly improved) and those who unimproved were defined using a 5-point global rating chance scale (GROC). Responsiveness was assessed using effect size and standardized response mean (SRM). ES has observed the mean change scores divided by the standard deviation of the initial score. SRM was calculated for the improved group and the unimproved group, dividing the mean change scores by the standard deviation of mean change scores. Similar to effect size, SRM values and ES values of $0.20,0.50$ and 0.80 were considered small, moderate or large, respectively.

Results: Forty-eight patients $(84.21 \%$ ) were classified improved and 9 patients (15.79\%) were classified unimproved according to the GROC. Effect sizes and SRMs were large (greater than 1.00) for participants who were "much improved" or "slightly improved" on the GROC for both the DASH and UEFI. For groups of participants who improved on the GROC, effect sizes and SRMS were ranged from 1.87 to 2.09 and 2.13 to 2.56 for the DASH, and 1.59 to 2.16 and 1.65 to 2.29 for the UEFI, respectively (Table 1).

Table 1. Mean baseline scores, change scores, effect size and standardized response mean for improved and unimproved patients

\begin{tabular}{lccc}
\hline $\begin{array}{l}\text { Global Rating of } \\
\text { Change }\end{array}$ & \multicolumn{2}{c}{ Improved $(\mathbf{n}=\mathbf{4 8})$} & Unimproved (n=9) \\
\cline { 2 - 4 } & $\begin{array}{c}\text { Much Improved } \\
(\mathbf{n}=\mathbf{2 7})\end{array}$ & $\begin{array}{c}\text { Slightly Improved } \\
(\mathbf{n}=\mathbf{2 1})\end{array}$ & $\begin{array}{c}\text { No Change } \\
(\mathbf{n}=\mathbf{9})\end{array}$ \\
\cline { 2 - 4 } & Mean (SD) & Mean (SD) & Mean (SD) \\
\hline The disabilities of the arm, shoulder and hand & & \\
Baseline & $43.41(14.22)$ & $42.66(13.41)$ & $44.21(7.24)$ \\
After 6-week & $13.65(11.60)$ & $17.51(8.91)$ & $39.72(6.81)$ \\
Change & $-29.75(11.61)$ & $-25.14(11.77)$ & $-4.48(3.26)$ \\
ES & 2.09 & 1.87 & 0.61 \\
SRM & 2.56 & 2.13 & 1.37 \\
The upper extremity functional index & & \\
Baseline & $42.00(10.15)$ & $42.76(15.75)$ & $39.75(9.85)$ \\
After 6-week & $64.00(10.53)$ & $67.47(11.47)$ & $47.00(5.39)$ \\
Change & $22.00(9.60)$ & $24.71(14.96)$ & $7.25(6.47)$ \\
ES & 2.16 & 1.56 & 0.73 \\
SRM & 2.29 & 1.65 & 1.12 \\
\hline Abbris & &
\end{tabular}

Abbreviations: ES, Effect Size; SD, Standard Deviation; SRM, Standardised Response Mean.
Conclusion: These findings showed that for patients receiving physiotherapy for the management of elbow stiffness, both the DASH and the UEFI are similarly responsive to change in symptoms and disability and similarly able to discriminate between patients who improved or unimproved.

References:

[1] Hudak PL, Amadio PC, Bombardier C. Development of an upper extremity outcome measure: the DASH (disabilities of the arm, shoulder and hand) The Upper Extremity Collaborative Group (UECG). American journal of industrial medicine. 1996;29(6):602-8.

[2] Stratford PW, Binkley JM, Stratford DM. Development and initial validation of the upper extremity functional index. Physiotherapy Canada 2001;53(4):259-67.

[3] Smith MV, Calfee RP, Baumgarten KM, Brophy RH, Wright RW. Upper extremity-specific measures of disability and outcomes in orthopaedic surgery. The Journal of bone and joint surgery American volume. 2012;94(3) 277-85.

Characters from table content including title and footnotes: 783

Disclosure of Interests: None declared

DOI: 10.1136/annrheumdis-2020-eular. 1629

\section{THU0610-HPR PREDICTION EQUATION FOR MUSCLE MASS OVERESTIMATES MUSCLE MASS IN PATIENTS WITH RHEUMATOID ARTHRITIS}

R. Cavalheiro Do Espírito Santo ${ }^{1,2}$, L. Santos ${ }^{1,2}$, L. Filippin ${ }^{3}$, P. Lora ${ }^{4}$,

R. Xavier ${ }^{1,2} .{ }^{1}$ Hospital de Clínicas de Porto Alegre, Serviço de Reumatologia, Porto Alegre, Brazil; ${ }^{2}$ Universidade Federal do Rio Grande do Sul, Porto Alegre, Brazil; ${ }^{3}$ Universidade La Salle, Canoas, Brazil; ${ }^{4}$ Universidade do Vale do Rio dos Sinos, São Leopoldo, Brazil

Background: Rheumatoid Arthritis (RA) is a chronic, progressive, inflammatory autoimmune disease characterized by systemic manifestations. Often is observed in RA patients changes in body composition, such as reduced mus cle mass (sarcopenia) with stable or increased fat mass (FM) [1]. Total-body skeletal muscle mass (SMM), specifically appendicular skeletal muscle, is a key diagnostic feature for the assessment of geriatric syndromes associated with skeletal muscle wasting, such as sarcopenia [2]. Estimation of SMM can be accomplished by a variety of methods, but the majority that considered the gold standard for this purpose are high cost. Due high cost, this methods are unfeasible in population studies and increases the difficulty of use in different clinical contexts. Predictive equations have been developed for estimation of whole-body skeletal muscle mass on the basis of anthropometric data, which can be collected in a more affordable manner, in an attempt to make SMM calculation easier and enable its use in epidemiological research and in clinical settings [3]. However, these equations were not developed for RA populations.

Objectives: To compare the anthropometric equation that estimate SMM with body composition measurements derived from DXA in RA patients.

Methods: Ninety patients diagnosed with RA according to ACR/EULAR criteria were recruited. Body composition was assessed by total body dual-energy $x$-ray absorptiometry (DXA) for measurement of appendicular lean mass index (ALMI $\mathrm{kg} / \mathrm{m} 2$ ). The prediction equation for muscle mass proposed by Lee et al (variables included: body weight, height, age, sex and race) was used to generate estimates of SMM, stratified by BMI. Frequency analysis, independent student's $t$ test and intraclass correlation coefficients (ICC) were performed. Statistical significance was considered as $\mathrm{p}<0.05$

Results: Of the 90 patients analyzed, most were women (86.7\%; 78/91), with mean age of $56.5 \pm 7.3$ and median disease duration time of 8.5 (3-18) years. The mean of BMI was $27.39 \pm 5.14$. Thirty $(33.3 \%)$ RA patients had normal weight, forty patients (44.4\%) were overweight and twenty patients $(22.2 \%)$ were obese In normal weight patients, just like overweight and obese patients, the estimates of SMM obtained by Lee equation were higher than those obtained by DXA measurements(Obese: Lee $10.66 \pm 1.19$ vs DXA 7.10 \pm 0.73 ; Overweight: Lee $8.63 \pm 0.99$ vs DXA $6.57 \pm 0.82$; Normal weight: Lee $7.14 \pm 0.85 v s$ DXA $6.03 \pm 0.71$ $\mathrm{p}<0.05)$. The Lee equation estimates showed ICC of $0.78(0.66-0.85)$ with DXA measurements. When stratified by BMI, Lee equation showed ICC of $0.87(0.72$ - 0.94) for normal weight, $0.83(0.68-0.91)$ for overweight and $0.77(0.42-0.90)$ for obese with DXA.

Conclusion: The muscle mass index by Lee equation overestimates the muscle mass in overweight or obese RA patients compared to DXA. Thus, sarcopenic RA patients may be wrongly classified as normal by the equation. This is probably related to the obese cachexia that these patients often present. More studies are necessary to analysis to better prediction equations for muscle mass in RA patients.

\section{References:}

[1] Smolen JS et al. Nat Rev Dis Prim. 2018;4:18001; [2] Kim J et al. Am J Clin Nutr 2002; 76: 378-83.; [3] Lee RC et al. Am J Clin Nutr 2000;72:796-803. 
Acknowledgments: We thank the Coordination for the Improvement of Higher Level Personnel (Coordenação de Aperfeiçoamento de Pessoal de Nível Superior-CAPES) institution, the Foundation for Research Support of the Rio Grande do Sul State (Fundação de Amparo à Pesquisa do Estado do Rio Grande do Sul-FAPERGS), the Research and Events Incentive Fund (Fundo de Incentivo à Pesquisa e Eventos-FIPE) of HCPA and Technological Development (Conselho Nacional de Desenvolvimento Científico e Tecnológico-CNPq).

Disclosure of Interests: Rafaela Cavalheiro do Espírito Santo: None declared, Leonardo Santos: None declared, Lidiane Filippin: None declared, Priscila Lora: None declared, Ricardo Xavier Consultant of:AbbVie, Pfizer, Novartis, Janssen, Eli Lilly, Roche DOI: 10.1136/annrheumdis-2020-eular.2870

\section{THU0611-HPR MEASUREMENT OF MINIMAL DISEASE ACTIVITY IN PSORIATIC ARTHRITIS USING PROMIS-PHYSICAL FUNCTION OR THE HEALTH ASSESSMENT QUESTIONNAIRE-DISABILITY INDEX}

E. Chew ${ }^{1}$, J. Perin ${ }^{2}$, T. Grader-Beck', A. M. Orbai ${ }^{1} .{ }^{1}$ Johns Hopkins Hospital, Rheumatology, Baltimore, United States of America; ${ }^{2}$ Johns Hopkins University School of Public Health, Baltimore, United States of America

Background: Minimal disease activity (MDA) is a treat-to-target strategy (T2T) objective in psoriatic arthritis (PSA). MDA criteria, include physical function, traditionally assessed via the Health-Assessment Questionnaire Disability Index (HAQ-DI). It is of interest to assess the performance of more current physical function instruments such as the Patient-Reported Outcomes Measurement Information System-Physical Function Profile (PROMIS-PF).

Objectives: To assess the interchangeability of the HAQ-DI with the PROMIS-PF in the calculation of MDA in PsA.

Methods: Longitudinal PsA data were collected including HAQ-DI and PROMIS-PF in a PsA cohort. MDA definitions were built substituting the HAQ-DI criterion with the PROMIS-PF short form 4a (PROMIS-PF4a) or with the PROMIS-PF computer adaptive test (PROMIS-PF Bank). We assessed agreement/accuracy between HAQ-DI based and PROMIS-PF based MDA definitions at each visit and longitudinally through the kappa statistic/ROC curve analysis. Results: One hundred participants contributed 352 observations with up to five visits. Mean (SD) age was 52 (12) years, $60 \%$ were female, and $43 \%$ were in MDA at baseline. Kappa statistic for PROMIS-PF based MDA reflected almost perfect agreement with HAQ-DI MDA: kappa=0.94 (95\% Cl 0.90-0.97) for MDA PROMIS-PF Bank, and kappa $=0.90$ ( $95 \% \mathrm{Cl} 0.80-0.95)$ for MDA PROMISPF4a. Higher longitudinal agreement was seen between MDA HAQ-DI and MDA PROMIS-PF Bank versus MDA PROMIS-PF4a between consecutive visits:

Table 1. Agreement between HAQ-DI based MDA and PROMIS-PF based MDA definitions at each visit and longitudinally

\begin{tabular}{|c|c|c|c|c|c|}
\hline Agreement & & Visit 1 & Visit 2 & Visit 3 & Visit 4 \\
\hline MDA HAQ-DI and & Kappa & 0.91 & 0.93 & 0.92 & 0.83 \\
\hline \multirow[t]{2}{*}{ MDA PROMIS-PF4a } & $95 \% \mathrm{Cl}$ & $(0.80-0.98)$ & $(0.82-1.00)$ & $(0.80-1.00)($ & $(0.66-0.96)$ \\
\hline & $\mathrm{N}$ & 86 & 81 & 72 & 58 \\
\hline MDA HAQ-DI and & Kappa & 0.91 & 0.98 & 0.94 & 0.93 \\
\hline \multirow[t]{2}{*}{ MDA PROMIS-PF4a } & $95 \% \mathrm{Cl}$ & $(0.81-0.98)$ & $(0.90-1.00)$ & $(0.84-1.00)($ & $(0.82-1.00)$ \\
\hline & $\mathrm{N}$ & 86 & 82 & 73 & 58 \\
\hline Longitudinal agreement & & $\begin{array}{l}\text { Visit } 1 \text { to } \\
\text { visit } 2\end{array}$ & $\begin{array}{l}\text { Visit } 2 \text { to } \\
\text { visit } 3\end{array}$ & $\begin{array}{c}\text { Visit } 3 \text { to } \\
\text { visit } 4\end{array}$ & $N / A$ \\
\hline MDA HAQ-DI state change with & Kappa & 0.75 & 0.84 & 0.72 & N/A \\
\hline \multirow[t]{2}{*}{ MDA PROMIS-PF4a state change } & $95 \% \mathrm{Cl}$ & $(0.47-0.95)$ & $(0.58-1.00)$ & $(0.37-0.94)$ & \\
\hline & $\mathrm{N}$ & 71 & 67 & 51 & \\
\hline MDA HAQ-DI state change with MDA & Kappa & 0.81 & 0.94 & 0.84 & N/A \\
\hline \multirow[t]{2}{*}{ PROMIS-PF Bank state change } & $95 \% \mathrm{Cl}$ & $(0.49-1.00)$ & $(0.75-1.00)$ & $(0.48-1.00)$ & \\
\hline & $\mathrm{N}$ & 72 & 68 & 52 & \\
\hline
\end{tabular}

${ }^{*}$ Bias corrected $95 \% \mathrm{Cl}$ were calculated using bootstrapping with 2000 repetitions of individual patients.

MMDA state changes are defined as transitions in the respective MDA state between designated consecutive visits

Abbreviations: $\mathrm{Cl}$ confidence interval; $\mathrm{N}$ number of observations; HAQ-DI Heath Assessment Questionnaire-Disability Index; PROMIS-PF4a Patient Reported Outcomes Measurement Information System Physical Function form 4a; PROMIS-PF Bank Patient Reported Outcomes Measurement Information System Physical Function Bank administered as a computer adaptive test; MDA HAQ-DI Minimal disease activity includes the HAQ-DI $\leq 0.5$ criterion; MDA PROMIS-PF4a includes the PROMIS-PF4a $\geq 41.3$ criterion; MDA PROMIS-PF Bank includes the PROMIS-PF CAT $\geq 41.3$ criterion kappa ranged between 0.81-0.94 versus 0.72-0.84, respectively (Table 1). Area under ROC curve for predicting MDA HAQ-DI was 0.97 for MDA PROMIS-PF Bank and 0.95 for MDA PROMIS-PF4a (Figure 1).
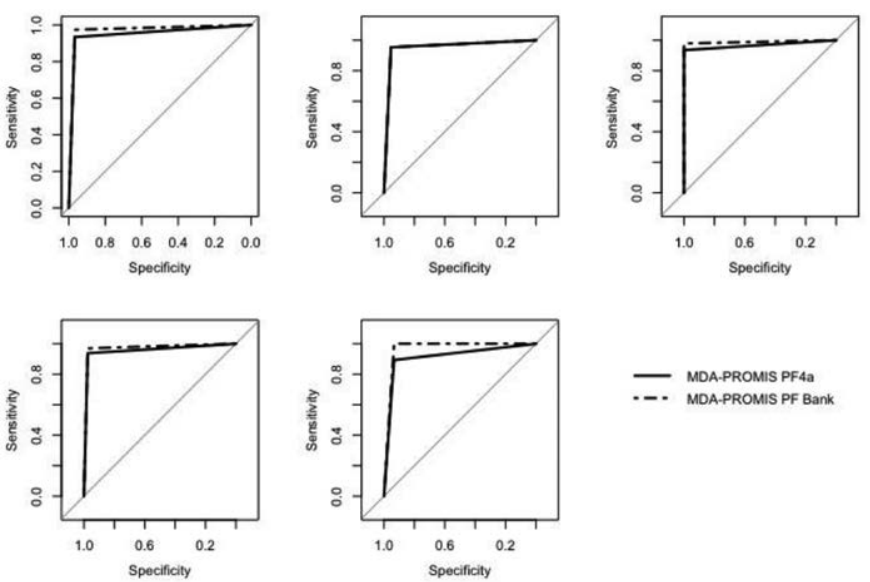

Figure 1. Areas under receiver operative characteristic curve to predict $H A Q-D I$ based MDA using MDA PROMIS-PF4a or MDA PROMIS-PF Bank at each visit and overall using all observations (from left to right: visit 1, 2, 3, 4, and overall across visits)

Conclusion: Excellent agreement was seen between HAQ-DI and PROMISbased MDA definitions statically and longitudinally. The PROMIS-PF Bank and PROMIS-PF4a are accurate replacements for the HAQ-DI in calculating MDA state in PsA.

References:

[1] Schalet BD, et al. J Gen Intern Med 2015

Disclosure of Interests: Erin Chew: None declared, Jamie Perin: None declared, Thomas Grader-Beck Grant/research support from: Abbvie, Celgene, Consultant of: Novartis, Lilly, Ana-Maria Orbai Grant/research support from: Abbvie, Eli Lilly and Company, Celgene, Novartis, Janssen, Horizon, Consultant of: Eli Lilly; Janssen; Novartis; Pfizer; UCB. Ana-Maria Orbai was a private consultant or advisor for Sun Pharmaceutical Industries, Inc, not in her capacity as a Johns Hopkins faculty member and was not compensated for this service.

DOI: 10.1136/annrheumdis-2020-eular.212

\section{THU0612-HPR DOES PAIN AND COMORBIDITY BURDEN PREDICT FRAILTY IN PATIENTS WITH KNEE-OSTEOARTHRITIS? FINDINGS FROM THE RESEARCH ON OSTEOARTHRITIS AGAINST FRAILTY (ROAF) STUDY.}

F. Salaffi ${ }^{1}$, M. Carotti ${ }^{2}$, S. Farah ${ }^{1}$, M. DI Carlo ${ }^{1}$, A. Giovagnoni ${ }^{2} .{ }^{1}$ Hospital "Carlo Urbani", Università Politecnica delle Marche, Scienze Cliniche e Molecolari, Jesi, Italy; ${ }^{2}$ Ospedali Riuniti Torrette Di Ancona, Radiologia, Torrette, Ancona, Italy

Background: Pain and comorbidity burden has been suggested to act as a stressor during aging, potentially accelerating declines in health and functioning in patients with osteoarthritis of the knee (KNEE-OA) $(1,2)$.

Objectives: The aims of the present research were to assess (i) the prevalence of frailty and (ii) its potential associated factors in a cohort of adult patients with KNEE-OA.

Methods: Patients fulfilling the clinical American College of Rheumatology knee-OA criteria were assessed according to the Survey of Health, Ageing and Retirement in Europe Frailty Instrument (SHARE-FI), and classified as frail, prefrail, or non-frail. The clinical evaluation included the following items: Western Ontario and McMaster Universities Osteoarthritis Index (WOMAC) Pain subscale (3) and Medical Outcomes Study Short Form-36 (SF-36). Evaluation of the comorbidities burden was performed with the modified Rheumatic Disease Comorbidity Index (mRDCl). Radiographic knee OA was defined according to Kellgren/Lawrence (KL) grades. Chi-square, analysis of variance (ANOVA), and multinomial logistic regression analyses were used to test the prognostic value of frailty for the outcomes of interest. 